\title{
1.3. Lección Inaugural \\ Notas sobre la cooperativa, el socio \\ y la norma tributaria
}

\author{
Tulio Rosembuj
}

Catedrático de Derecho Financiero y Tributario de la Universidad de Barcelona

1. El fomento a la sociedad cooperativa no es un concepto vacío y caprichoso: tiene su fundamento preciso en la Constitución (art.129.2), que, en su vértice, construye una posición subjetiva, un favor iuris, de la cooperativa como específico tipo societario.

La sociedad cooperativa aparece como sujeto destinatario de protección preferente y ello en base al concepto jurídico indeterminado de adecuada legislación, adecuación respecto a la cultura cooperativa preexistente que llega a la norma jurídica, ordenada en sus requisitos distintivos.

Esto significa, en principio, que la norma jurídica favorece (y debe hacerlo) eliminando discriminación negativa sobre la configuración y tratamiento de la cooperativa y, más aún, adaptando su horma a la predefinición sociológica que nutre los principios culturales de la cooperativa.

La legislación adecuada admite, entonces, su contrario: norma cooperativa inadecuada, en cuanto no recoge sus líneas básicas o tiene la pretensión de imponerse a las que lo son, en la realidad preexistente, que aspira a disciplinar.

2. Esa libertad del legislador (¿De qué hablamos cuando hablamos de ley adecuada?) puede tener, al menos, dos orientaciones, o el interés social, el interés común de los socios, se reconoce en el interés singular, propio de cada socio; o el interés social se reserva y tutela en cabeza de la sociedad que integra. En términos simples, la sociedad cooperativa es dependiente o autónoma del interés del socio en sí 
mismo considerado. Es evidente que cualquiera de las direcciones es legítima, puesto que coexisten desde siempre en el seno del movimiento cooperativo: la cooperativa como instrumento inmediato y directo de satisfacción de las necesidades de los socios o al servicio de fines trascendentes, de naturaleza política, religiosa, sindical. (1)

La legislación adecuada para la sociedad puede no serlo para el socio o viceversa. La horma de la cooperativa como institución por encima y más allá del interés del socio o la cooperativa del socio como medio servil de su interés.

Los beneficios fiscales y los estímulos subvencionales no ofrecen idéntico perfil según sea la perspectiva adoptada, la del socio o de la sociedad cooperativa.

Hay una exigencia de interpretación desdoblada que permite diferenciar los efectos de la norma jurídica adaptada o al interés social objetivo de la sociedad o al interés social subjetivo del socio.

La cooperativa existe fundamentalmente «para el beneficio de sus afiliados» (Declaración de la A.C.I. sobre Identidad Cooperativa, 1995).

3. La definición de cooperativa destaca su carácter contractual, como fruto de la autonomía privada; para asociar personas, físicas o jurídicas, en forma voluntaria — libres de asociarse o desafiliarsedestinada esencialmente a atender las necesidades de sus miembros, con la idea que el socio es el verdadero protagonista de cualquier aventura cooperativa, en condiciones más favorables que las que ofrece el mercado. La cooperativa del socio implica la distribución de la propiedad entre los miembros sobre una base democrática: la cooperativa es propiedad privada de los socios, en razón de la actividad y en proporción a sus operaciones: y de carácter empresarial: la cooperativa es una organización de factores de producción que actúa en el mercado, en circunstancias análogas a cualquier otra empresa.

El núcleo esencial del tipo cooperativo es el socio. Y su finalidad no puede ser otra que la de orquestar la (mejor) satisfacción de sus intereses sociales, económicos y culturales.

Si la persona del socio incardina la causa contractual y expone el interés social; la norma tributaria adecuada es aquella que toma como punto de partida la sociedad y punto de llegada al socio: la capacidad económica, en su caso, siempre será la que exhibe el socio mediante o a través de la organización societaria. 
La cooperativa, entonces, es el dispositivo utilizado por el socio para reemplazar otros agentes económicos, eliminando ese margen de beneficio en su favor.

4. Si hay un tiempo para que se produzca la vis atractiva de la imposición, sea para su gravamen o exclusión; este momento no es otro que el del reemplazo de la actividad mercantil ordinaria por la actividad cooperativizada.

La ventaja patrimonial del socio, ya como ahorro en el gasto o mayor retribución o, como se verá, si las reservas son repartibles, es consecuencia de la apropiación del margen de beneficio de la actividad objeto de sustitución. Esta ventaja patrimonial se realiza mediante la cooperativa que acerca el beneficio, medido al sacrificio propio del socio. (2)

La función de la sociedad está vinculada, hacia dentro, a la satisfacción de las necesidades económicas específicas de los socios, un ámbito común para la realización de su interés directo. Pero, el efecto de la actividad cooperativa, hacia fuera, es la sustitución de alguna actividad económica de otros para sí (la sociedad lucrativa, el sector público en materia de servicios públicos).

La apropiación del margen de beneficio ajeno, por la actividad cooperativizada, recupera, para el socio, el valor añadido que se desprende de su compromiso y responsabilidad asumida. Esa ventaja patrimonial siempre será simétricamente equivalente a la desventaja patrimonial que otra actividad llevada a cabo por otro agente económico (privado o público) obtenía la cooperativa.

La sustitución o reemplazo del intermediario despeja la idea de finalidad autónoma de la cooperativa respecto a la iniciativa del socio. Al contrario, si algo hay que destacar consiste en su dependencia.

5. La sustitución total o parcial, complementaria o excluyente sirve a la actividad de integración inherente a la fórmula cooperativa. La entidad significa una propuesta de relevo para el desarrollo de un espacio común, en relación a agentes económicos preexistentes. La apropiación del beneficio ajeno por el socio equivale al aprovechamiento de la ventaja patrimonial que ahora le enriquece, así como previamente le empobrecía.

La cooperativa es una sociedad legítima de interposición (una sociedad interpuesta por los socios para la consecución del fin propues- 
to). No es que la intervención sea de la sociedad, sino de sus miembros y son éstos los que actúan en lugar de otros, antes.

La cooperativa es una empresa órgano de integración de la economía de los socios.

Por eso, aunque seguramente con propósitos distintos, el legislador fiscal atina en la cualificación de conjunto vinculado a la relación jurídica económica entre socio y cooperativa. En efecto, la obligada sujeción de las operaciones realizadas por la cooperativa con sus socios al criterio del conjunto vinculado, lo cual supone su cálculo por su valor de mercado como si fueran empresas independientes, indica que la subordinación de la sociedad a socio es real y efectiva, condicionando en modo determinante su autonomía de decisión, si la tuviera.

El legislador está señalando al socio como titular del poder de decisión o de influencia en la gestión y dirección societaria y emplea el valor de mercado en evitación de prácticas irregulares de reparto de ingresos o gastos. La ficción jurídica del valor de mercado es una verdad distinta a la verdad jurídica real y efectiva: la norma tributaria postula la independencia en la valoración de la operación cooperativizada, precisamente, porque, en puridad, no hay independencia alguna que separe la sociedad de la decisión del socio.

El valor de mercado es un indicador preciso que comporta consecuencias destacadas. La cooperativa como órgano dependiente de los socios tiene el contorno fiscal de centro de imputación subjetiva de renta, un instrumento pasivo del socio y una mera forma de producción de rendimiento destinado a los miembros. (3)

6. Teóricamente, si hay un contribuyente, en sentido técnico, éste no puede ser otro que el socio cooperativo; puesto que, a través de sus ventajas patrimoniales exhibe o puede hacerlo, capacidad económica.

La renta que el socio puede conseguir a través de la cooperativa le pertenece en proporción a su actividad con la propia sociedad. Precisamente, el retorno es la compensación diferida de las prestaciones cooperativas, sin relación alguna con la aportación al capital social suscrita o desembolsada, en base a las compras efectuadas (cooperativas de consumo), al valor de los bienes y servicios aportados (cooperativas de producción) o a la magnitud del trabajo (cooperativas de trabajo asociado). (4) 
La cooperativa es un haz de derechos subjetivos centralizados. Para ello su función es integradora y complementaria de la economía de los socios. Asimismo sustituye etapas del circuito económico a través de la eliminación de intermediarios en la gestión que realiza. De estos caracteres deriva la concepción del tipo cooperativo: es una sociedad, en símisma desinteresada, carente de interés peculiar propio, organizada, por definición, desde y hacia la gestión del servicio al socio y cuyo valor capital no es el de la sociedad mercantil, sino el valor de las prestaciones del socio con la entidad. Pero, esta composición es coherente siempre que la cooperativa administre en su plenitud, y sea administrada, en la gestión de servicios al socio. El socio contribuyente de una entidad servil e instrumental es la denominación estricta de la cooperativa. La causa del contrato es la unión voluntaria para satisfacer necesidades propias de naturaleza económica, social, cultural, por lo que sería incongruente extender las conclusiones más allá de la relación entre el socio y su entidad, entre el socio y la actividad cooperativizada. La fiscalidad de la cooperativa aflora en sus referencias al no socio, sea consumidor, trabajador, productor. El resultado que deriva de la actividad con el tercero no socio es beneficio, ganancia, de la cooperativa y no pueden dar lugar ni a renta a favor del socio, excepto como dividendo, que no como retorno y al mismo tiempo, supone una manifestación concreta de la capacidad económica de la cooperativa en cuanto tal.

7. Así como el socio aparece como el contribuyente en el diseño de una relación plena, absoluta y exclusiva con la sociedad, puesto que resulta el titular de las ventajas patrimoniales que pueden ocasionarse; se impone la no sujeción o exclusión de la cooperativa del deber de contribuir. La renta cooperativa será siempre la que se procura el socio, puesto que, en rigor, la cooperativa no demuestra capacidad económica autónoma y separada ni es la titular efectiva de la riqueza originada. El socio podrá o no gozar de beneficios fiscales. Esto dependerá del legislador. Pero, lo que es indiscutible es que si se produce renta cooperativa será siempre la del socio, que no de la sociedad que le sirve de cauce. La no sujeción o exclusión de la cooperativa, como tendencia, significa que, si está al servicio del socio, no demuestra capacidad económica específica, ni realiza el hecho imponible, no estando comprendida en el ámbito de actuación del tributo (sobre el beneficio o renta). La idea implica que la cooperativa es una sociedad transparente por definición (partnership approach) y en la que el modo perfecto de gravamen está localizado en cada uno de sus socios, en la proporción medida de su relación con la sociedad. 
Esto cambia cuando ocurren resultados extracooperativos, a consecuencia de afrontar la realización de actividad ajena al objeto social, a sus fines o con terceros no socios. La cooperativa que obtiene resutados extracooperativos está sometida a tratamiento análogo al de cualquier otra sociedad mercantil, porque de lo contrario, se crearía un supuesto de competencia desleal con aquella sociedad que no lo es y carece de cualquier beneficio fiscal.

No tiene fundamento alguno defender el beneficio fiscal sobre el resultado extracooperativo, porque se practica una discriminación objetiva, en contra de la sociedad que, a paridad de circunstancias, no tiene la forma cooperativa.

El socio partícipe de los resultados desvinculdaos de su propia actuación estaría sometido a la condición análoga del accionista, puesto que la utilidad obtenida no se destacaría materialmente del dividendo, aunque se ajuste a su actividad cooperativizada, antes que al capital aportado.

8. El concepto de resultado extracooperativo se apoya en la actividad llevada a cabo por la cooperativa con terceros no socios o extraña a su objeto social. La extensión a terceros de las ventajas patrimoniales practicadas a los socios no se compadece, en términos fiscales, con la actividad interna entre los socios y su cooperativa. La proyección externa de la cooperativa, a partir de la decisión de los socios, tiene un contenido preciso: destinar una parte del excedente al desarrollo sostenible de la propia comunidad (el principio ACI de interés hacia la comunidad). Pero, esa finalidad no es similar a la emigración de la ventaja patrimonial fuera del círculo del socio o del objeto social propuesto.

El resultado extracooperativo es beneficio mercantil de la sociedad y, en caso de reparto, dividendo para el socio. Es clara la sujeción al impuesto y la imputación al socio.

Al límite, si todo el resultado de la cooperativa es extracooperativo, estaría sometida al mismo tratamiento fiscal que cualquier otra sociedad mercantil en circunstancias análogas, aunque sin perder su calificación como coperativa. El socio recibe un dividendo, que no un retorno, porque su origen se encuentra en el acervo o patrimonio social. Es un puro rendimiento de capital mobiliario. El fruto (civil) de la aplicación, empleo o disposición del capital asociado. La retribución al socio es consecuencia de su actividad en y desde la cooperativa y no con ella, cualquier que sea el parámetro de reparto. 
La cooperativa expresa, entonces, plena capacidad económica y la percepción del socio es renta del capital. Si la tributación es análoga a la de cualquier otra sociedad también comportaría un crédito fiscal al socio para evitar la doble imposición, una vez sobre la entidad y después sobre el propio socio. El resultado cooperativo, en cambio, expone la no sujeción de la sociedad y la correlativa imputación, en su caso, de la ventaja patrimoniall al socio, en proporción a la actividad cooperativizada.

No es menos cooperativa la que se procura sus resultados del exterior, que otra. Lo único que se modifica es la aptitud de contribución al gasto público. Por un lado, la doble capacidad económica, de la sociedad y del socio; por otra, la capacidad económica singular del socio, que no de la cooperativa.

9. La sujeción del socio, que aquí se propugna, tiene, sin embargo, un obstáculo por superar. Las reservas irrepartibles deberían ajustarse al régimen de reserva legal cualquier otra sociedad mercantil. La capacidad económica del socio debe medirse no sólo por las ventajas patrimoniales (ahorro o retribución) relativas a su actividad cooperativizada o no, sino, además, por su participación en el reparto de las reservas durante la vida de la sociedad y a su disolución y liquidación. La lógica del beneficio fiscal siempre se ampara en la indisponibilidad de las reservas, sea durante la vida de la sociedad o a su culminación.

Si la cooperativa no aspira a protección alguna, porque por definición no está sujeta, y el socio queda sometido al impuesto sobre la renta, salvo que se le otorguen a él beneficios fiscales; la irrepartibilidad de las reservas penaliza los intereses de los socios sin argumento válido que lo justifique.

En cambio, si la protección fiscal se asienta sobre la cooperativa resulta lógico que se conserve la irrepartibilidad de las reservas, descartándolas de la base imponible del Impuesto sobre Sociedades.

El derecho positivo, de paso, no es congruente, porque sólo admite la reducción de un porcentaje, y no de la totalidad, del rendimiento neto destinado obligatoriamente al Fondo de Reserva. O sea, asume que las cantidades asignadas a la reserva irrepartible e indivisible entran en parte en el cómputo, a efectos de la base imponible pero, al mismo tiempo, no permite el reparto libre de la que resta entre los socios. 
La adecuación de la renta cooperativa a la capacidad económica del socio, mediante la transparencia fiscal, presupone que la reserva, salvo el mínimo de garantía legal para cualquier otra sociedad, fuera repartible entre los que contribuyen a su formación.

La existencia de un fondo de reserva legal en garantía de los acreedores y provisión de necesidades inesperadas no puede significar la expropiación de la actividad del socio, salvo que sea por propia decisión, para acogerse a los beneficios fiscales que lo estimulen. Pero, dejando abierta la posibilidad que, renunciando al beneficio fiscal, pueda ejercitar plena disposición sobre el excedente que genera.

10. La no sujeción de la cooperativa como criterio general de adecuada fiscalidad y el desplazamiento al socio del tributo sobre la renta obtenida no es óbice para la adecuada imposición del beneficio extracooperativo tanto en la sociedad cuanto sobre el socio. Y ello con fundamento en la libre opción de reparto o no de la reserva durante y al cese de la sociedad cooperativa, siempre que no se aspire a la exclusión del tributo por beneficio fiscal de la cooperativa o del socio.

En particular, el beneficio fiscal, si fuera el caso, debe centrarse en el socio: la fiscalidad del no-capital en el mercado es el eje. Pero, siempre, como ventaja directa del socio (trabajador, consumidor, empresario, comerciante) que no de la sociedad transparente (no sujeta) o gravada (por acto extracooperativo) y, por tanto, con méritos análogos a cualquier otra organización societaria.

El socio es el que debe recibir el beneficio fiscal. (5)

Primero, porque no se produce ninguna repercusión en la competencia leal entre la cooperativa y las demás fórmulas societarias, en posición par en el mercado. Segundo, porque el estímulo al socio cooperativo (persona física) significa actuar el principio de igualdad sustancial, favoreciendo la igualdad de oportunidades en la asunción del riesgo de empresa por quienes no detentan ni lo hacen bajo módulos de (posesión) capital. El beneficio fiscal se incrusta en el deber de remover obstáculos que impidan el ejercicio de la actividad económica o social por parte de los que tienen poder de disposición sobre bienes o servicios o lo tienen limitadamente. (6)

Tercero, porque el beneficio fiscal al socio no vulnera el principio de capacidad económica e iguadad tributaria (ex.art. 31 C.E.), teniendo en cuenta que son, finalmente, los obligados a la contribución al 
gasto público. La defensa de la protección fiscal del socio no empece a su carácter de sujeto pasivo del tributo y, por tanto, en suspensión de sus obligaciones tributarias en el ámbito del beneficio fiscal que pudiera concederse.

Cuarto, porque la eliminación o sustitución del intermediario por la cooperativa permite concentrar la esencia de la protección fiscal al socio en la asunción del riesgo de empresa por vía distinta al capital disponible, merecedor de la compensación que evite la discriminación negativa en contra de los que no lo detentan.

11. De las direcciones enunciadas, el legislador privilegia el tipo cooperativo sin socio. Es decir, una sociedad a cuyo resultado acumulado son extraños o ajenos y que desconoce o minusvalora el valor añadido singular de cada socio en su generación.

Toda la discusión del beneficio fiscal aparece alterada por dogmas excesivos. Ni las reservas deben ser totalmente irrepartibles al socio ni la actividad extracooperativa supone que la cooperativa deje de serlo.

Hay una economía de opción que el legislador debe respetar si pretende que disciplina sea la adecuada.

La cooperativa podría acogerse a la transparencia fiscal voluntariamente, probablemente rectificada, como en la Agrupación de Interés Económico, con la imputación de excedente positivo y negativo al socio; puesto que es el traje que mejor le sienta como conjunto vinculado. El socio sería el contribuyente por las ventajas patrimoniales que obtiene, con distribución de reserva por encima de la mínima legal exigible y el retorno, por ahorro en el gasto o mayor retribución.

La cooperativa cuyo resultado extracooperativo sea dominante estaría sujeta al tratamiento de cualquier otra sociedad mercantil y su beneficio distribuido convierte al socio en titular de dividendos por renta del capital (el valor neto patrimonial de la entidad es la fuente), excepto en las transacciones exclusivas con sus socios.

El contribuyente socio, finalmente, sería, en su caso, el único merecedor del beneficio fiscal, porque asume el riesgo de empresa de no-capital y es un medio favorecedor de la igualdad sustancial y material en la comunidad. Nada hay en la cooperativa que no sea del socio. Y, como es obvio, el fortalecimiento del socio impulsa el cooperativismo; aunque lo contrario, el fortalecimiento de la sociedad, no tenga un efecto similar. 
Sólo desde un observatorio histórico envejecido podría refutarse que la protección fiscal del socio es lo único adecuado para que la cooperativa encuentre la complicidad del Estado en su fomento.

Con la disciplina vigente, puede que la fiscalidad sirva a (alguna) cooperativa; pero enfáticamente, no al socio ni al principio de igualdad material.

\section{Bibliografía}

(1) BAssı Amedeo, Le Societá Cooperative, Ed. UTET, Turín 1995.

(2) Buonocuore Vincenzo, Diritto della cooperazione, Ed. II Mulino, Bolonia, 1997.

(3) Rosembuj Tulio, Régimen Fiscal de las Cooperativas, Ed. PPU, Barcelona, 1999.

(4) Rosembus Tulio, La Cooperativa y la Norma Tributaria, Tribuna Fiscal, n. ${ }^{\circ}$ 19, 1976.

(5) Rosembus Tulio, Reinventar la Cooperativa, separata de R.E.S.E. n. ${ }^{\circ} 26$, Barcelona, 1997.

(6) Schiano Giorgio y Graziano Fabio, La Societá Cooperativa: aspetti civilistici e tributari, Ed. Antonio Milani, 1997. 